\title{
Research progress on evodiamine, a bioactive alkaloid of Evodiae fructus: Focus on its anti-cancer activity and bioavailability (Review)
}

\author{
CHAODAN LUO, JINGWEN AI, ERFANG REN, JIANQIANG LI, \\ CHUNMEI FENG, XINRONG LI and XIAOJIE LUO
}

\begin{abstract}
Subtropical Agricultural Products Processing Engineering Technology Center, Guangxi Institute of Subtropical Agricultural Products Processing, Guangxi Subtropical Crops Research Institute, Guangxi Academy of Agricultural Sciences, Nanning, Guangxi 530001, P.R. China
\end{abstract}

Received February 18, 2021; Accepted August 17, 2021

DOI: $10.3892 /$ etm.2021.10762

\begin{abstract}
Evodiae fructus (Wu-Zhu-Yu in Chinese) can be isolated from the dried, unripe fruits of Tetradium ruticarpum and is a well-known traditional Chinese medicine that is applied extensively in China, Japan and Korea. Evodiae fructus has been traditionally used to treat headaches, abdominal pain and menorrhalgia. In addition, it is widely used as a dietary supplement to provide carboxylic acids, essential oils and flavonoids. Evodiamine (EVO) is one of the major bioactive components contained within Evodiae fructus and is considered to be a potential candidate anti-cancer agent. EVO has been reported to exert anti-cancer effects by inhibiting cell proliferation, invasion and metastasis, whilst inducing apoptosis in numerous types of cancer cells. However, EVO is susceptible to metabolism and may inhibit the activities of metabolizing enzymes, such as cytochrome P450. Clinical application of EVO in the treatment of cancers may prove difficult due to poor bioavailability and potential toxicity due to metabolism. Currently, novel drug carriers involving the use of solid dispersion techniques, phospholipids and nanocomplexes to deliver EVO to improve its bioavailability and mitigate side effects have been tested. The present review aims to summarize the reported anti-cancer effects of EVO whilst discussing the pharmacokinetic behaviors, characteristics and effective delivery systems of EVO.
\end{abstract}

Correspondence to: Ms. Chaodan Luo, Subtropical Agricultural Products Processing Engineering Technology Center, Guangxi Institute of Subtropical Agricultural Products Processing, Guangxi Subtropical Crops Research Institute, Guangxi Academy of Agricultural Sciences, 21 Yongwu Road, Nanning, Guangxi 530001, P.R. China

E-mail: luochaodan1994@126.com

Key words: evodiamine, anti-cancer, pharmacokinetic, metabolism, bioavailability

\section{Contents}

1. Introduction

2. Anticancer activity

3. Pharmacokinetic characteristics

4. Approaches to improve the oral bioavailability

5. Conclusions and prospects

\section{Introduction}

Evodiae fructus (Wu-Zhu-Yu in Chinese) is the dried, unripe fruit of Tetradium ruticarpum, also known as Euodia rutaecarpa (1). Evodiae fructus is traditionally used as a medicinal herb in China, Japan and Korea (2). Evodiae fructus combined with Coptidis rhizome at a ratio of 6:1 (w/w) forms the well-known Chinese medicinal formula, Zuo-Jin-Wan, which is commonly used to treat different types of cancer including gastric and multidrug-resistant colorectal cancer cells (3-7). The anti-tumor effects of Evodiae fructus has been reported by a number of pharmacological studies $(8,9)$, where in one such study treatment with a $70 \%$ ethanol extract of Evodiae fructus inhibited the proliferation of prostatic hyperplasia-1 epithelial cells (9). Evodiae fructus is widely used as a dietary supplement to provide carboxylic acids, essential oils, flavonoids (10) and has been recorded in multiple versions of the Chinese Pharmacopoeia for its wide range of pharmacological activities (11).

Evodiamine (EVO; Fig. 1) is an alkaloid with a quinazolinocarboline skeleton (12). It is one of the major bioactive components that can be isolated from Evodiae fructus and has been reported to exert several pharmacological properties (13-17), including its ability to treat cancer, autoimmune and inflammatory disorders. In particular, the anti-tumor capacity of EVO has attracted the interest of researchers. EVO acts as a dual catalytic inhibitor of the nuclear enzyme topoisomerases I and II, which are vital anti-cancer drug targets (18). In addition, accumulating evidence suggests that EVO exhibits potential anti-cancer activities both in vivo and in vitro (19-21). 
EVO is considered to be a novel class of multi-target compounds that can be used to treat different types of cancer (16). In addition to topoisomerases, transient receptor potential cation channel subfamily V member 1(TRPV1) and the aryl hydrocarbon receptor (AhR) are considered direct protein targets of EVO (16). TRPV1 has been linked to processes mediating inflammation, cancer and cardiovascular and other disease $(22,23)$. AhR serves a functional role in physiology and toxicology, especially in cell proliferation and differentiation, the adaptive and toxic responses and immunomodulation $(24,25)$. However, the potential application of EVO in the clinic is hindered by its poor bioavailability due to limited absorption (26). Furthermore, similar to several anticancer drugs, such as doxorubicin, erlotinib, sunitinib and sorafenib, that can induce cardiotoxicity (27-29), EVO has been reported to induce cardiovascular side effects, including oxidative stress, both in vitro and in vivo (30). The cardiotoxicity of EVO has been investigated on primary cultured neonatal rat cardiomyocytes in vitro, and on zebrafish in vivo; EVO induced cardiac malfunction, which was evidenced by a decrease in the heart rate, as well as in circulation and pericardial malformations (30). In addition to cardiotoxicity, the issue of hepatotoxicity has also been raised with regards to the application and safety of EVO. It has been reported that the alkaloid-rich extract of Evodiae fructus is likely to cause hepatic injury in mice (31). As a major alkaloid compound contained within Evodiae fructus, hepatotoxicity mediated by EVO is induced by enhancing the activity of aspartate aminotransferase, alanine transaminase, lactate dehydrogenase and alkaline phosphatase (32).

Drug metabolism serves crucial roles in the bioavailability and subsequent pharmacological activities of poorly soluble, naturally occurring therapeutic agents, which significant impacts their toxicity profile and side effects (33). Previous studies have reported that the toxicity of EVO may be associated with its mechanism of metabolism in vivo and pharmacokinetics $(34,35)$. EVO is readily susceptible to metabolism, P450 enzymes-mediated dehydrogenation reactions may cause toxicity via formation of electrophilic intermediates, then produce glutathione (GSH)-conjugated metabolites to exert more potent cytotoxic effects than EVO itself (34). In addition, 10-hydroxyevodiamine and 11-hydroxyevodiamine are two primary toxic metabolites of EVO (36). Therefore, there is a demand to identify suitable EVO delivery systems for enhancing its bioavailability and bioactivity, in addition to alleviating the toxicity of EVO by regulating its metabolism and pharmacokinetics. The present review aims to summarize the potential mechanism of EVO in cancer therapeutics and discuss its pharmacokinetic characteristics. Finally, strategies designed to improve its oral bioavailability and alleviating its side effects are also mentioned.

\section{Anticancer activity}

Accumulating evidence suggests that EVO can exerts anticancer effects both in vitro and in vivo. Numerous types of cancer cell lines derived from different organs have been reported to have their physiological characteristics inhibited by EVO (Fig. 2; Table I). As shown in Table I, the antitumor effects of EVO has been reported mainly in colon cancer, lung cancer, hepatocellular carcinoma and melanoma, suggesting that EVO may exert more favorable effects in the treatment of these tumors. EVO can exert a range of different physiological mechanisms, including inhibition of proliferation, induction of apoptosis, reduction of migration/invasion and inhibition of metastasis (37). The alkyl group on position N-14 and the configuration of hydrogen at position $\mathrm{C}-13 \mathrm{~b}$ of EVO has been reported to mediate its antitumor effects $(38,39)$.

Induction of apoptosis. Apoptosis is a programmed mechanism of cell death that can eliminate foreign or malignant cells to protect organisms against cancer, in addition to being important for normal development (40). EVO is a potent inducer of apoptosis in human non-small-cell lung cancer A549 cells (41), where EVO-induced apoptosis has been observed to occur downstream of mitotic arrest and subsequent mitotic slippage (42). The potential underlying mechanism of EVO on the induction of tumor cell apoptosis is presented in Fig. 3. EVO has been reported to induce apoptosis through both caspase-dependent and caspase-independent pathways (43). Apoptotic induction by EVO in human cervical cancer cells can be completely blocked by Pan-caspase inhibitors, suggesting that EVO induces cell apoptosis via the mitochondrial caspase-dependent pathway (44). In another study, EVO-induced apoptosis in human melanoma cells was not completely reversed by caspase inhibitor z-VAD-fmk (45). EVO has also been found to induce apoptosis in gastric cancer cells by inhibiting the mTOR signaling pathway, both in the presence and absence of z-VAD-fmk (46), suggesting that the caspase-independent cell death pathway is also involved in the proapoptotic mechanism of EVO. EVO can decrease the activity of the apoptosis suppressor Bcl-2 whilst increasing that of the apoptosis inducer Bax in tumor cells $(47,48)$, thereby activating initiator caspases (caspase-8 and 9) and the effector caspase (caspase-3) (49,50). Activation of the caspase-independent apoptotic pathway has been observed to be mediated by translocation of the apoptosis-inducing factor into the nuclei of human leukemia cells pretreated with EVO (43). Taken together, these findings suggest the role of the caspase-independent pathway in EVO against certain types of cancer cell line. Recently, EVO has been reported to induce human cholangiocarcinoma cell apoptosis by blocking the STAT3 signaling pathway, which is mediated by upregulating shatterproof 2 expression (51). In addition, generation of reactive oxygen species, nitric oxide $(52,53)$ and inactivation of the PI3K/AKT $(19,47,54-57)$ or PI3K/Protein Kinase C (PKC) (58) signaling pathways have been reported to serve promoting roles in EVO-induced apoptosis.

Inhibition of proliferation and cell cycle progression. EVO exerts potent antiproliferative effects on the cervical cancer cell line HeLa at the same concentration as those mediated by 2.4-dihydroxy-5-fluoropyrimidine (44). The reported underlying mechanism of action of EVO on the inhibition of proliferation and the cell cycle progression is summarized in Fig. 4. EVO suppresses proliferation by cell cycle arrest at the $\mathrm{G}_{2} / \mathrm{M}$ phase $(50,59-62)$. EVO can block the cell cycle at the $\mathrm{G}_{2} / \mathrm{M}$ phase of human gastric adenocarcinoma SGC-7901 and breast cancer NCI/ADR-RES cells in a dose-dependent 


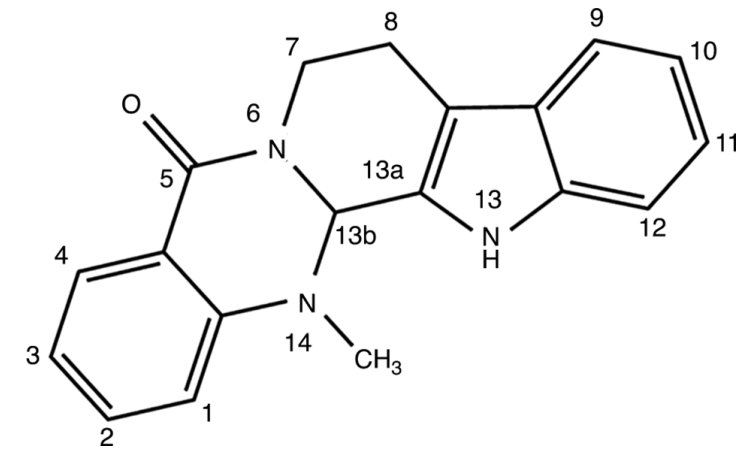

Figure 1. Structure of evodiamine.

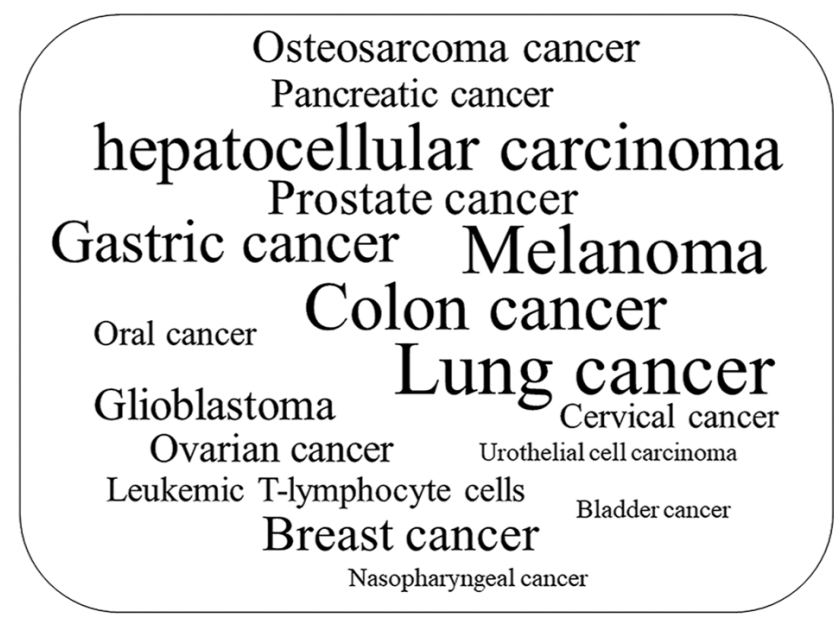

Figure 2. Different types of cancer cells that have been reported to be inhibited by evodiamine. These tumor cells are referred to as a 'word cloud', where the size of each name is proportional to the number of publications that reported inhibitory effects in their respective the cancer type $(9,25-100)$.

manner, with prominent arrest at both the sub- $\mathrm{G}_{1}$ and $\mathrm{G}_{2} / \mathrm{M}$ phases observed in NCI/ADR-RES cells with longer incubation times $(62,63)$. The phosphorylation of Cdc2 occurs on three regulatory sites: Threonine 14 (Thr14), tyrosine 15 (Try15, the inactive form) and threonine 161 (Thr161, the active form) (64). Phosphorylation of Cdc2 on Thr161 results from the concurrent inhibition of Wee-1 and Myt-1 and activation of $\mathrm{Cdc} 25 \mathrm{C}$ phosphatase, leading to activation of $\mathrm{Cdc} 2 /$ cyclin B complex $(60,65)$. The $\mathrm{G}_{2} / \mathrm{M}$ arrest is accompanied by an increase in the protein expression of cyclin B1 and phosphorylated form of Cdc2 (Thr161) (60). EVO has been shown to arrest cell cycle at the $\mathrm{G}_{2} / \mathrm{M}$ phase in prostate cancer cells by significantly increasing the protein expression levels of activated Cdc2 (Thr161) and cyclin B1 whilst diminishing the activity of Myt-1 and unphosphorylated Cdc25C (59-61). The inhibitory effect of EVO on the proliferation of colon cancer LoVo cells occurred by S-phase arrest by decreasing the protein expression levels of cyclin A and Cdc25C (49). In addition, the peroxisome proliferator-activated receptor $\gamma(\operatorname{PPAR} \gamma)$ signaling pathway may be involved in the EVO-induced inhibition of the proliferation of leukemia cells. EVO exerts an inhibitory effect on proliferation of leukemia cells by enhancing expression of PPAR $\gamma$ via stimulating p21 and inhibiting cylin D1 (66).
Decreased invasion and metastasis. Metastasis is a major cause of cancer-associated mortality, where EVO may be a promising candidate for antitumor therapy by inhibiting metastasis (38). The roles of EVO in suppressing the invasion and metastasis of cancer cells are presented in Fig. 5. Hepatocyte growth factor (HGF) can promote the invasion and migration of different types of tumor cells (67). EVO has been reported to reverse HGF-stimulated invasion of colon 26-L5 carcinoma, B16-F10 melanoma and Lewis lung carcinoma cells in a dose-dependent manner, whereby $100 \%$ inhibition of HGF activity was achieved using $30 \mu \mathrm{M}$ EVO (68). Inhibition of MMP-2 expression and attenuation of ERK1/2 activation have also been documented to contribute to the anti-metastasis and anti-invasion effects of EVO on tumor cells (69). Previous studies found that EVO can inhibit the migration and invasion of colorectal cancer cells both in vitro and in vivo by decreasing MMP-9 expression and suppressing NF- $\kappa \mathrm{B} / \mathrm{p} 65$ nuclear translocation and acetylation $(69,70)$.

Other effects. Autophagy serves a synchronized role with apoptosis in the cytotoxic activities mediated by EVO (63). Blockade of angiogenesis also contributes to the anticancer activity of EVO $(71,72)$. EVO exerts antitumor effects by inhibiting the activation of $\mathrm{NF}-\kappa \mathrm{B}$ and therefore inhibits the transcription of $\mathrm{NF}-\kappa \mathrm{B}$-regulated gene products, including those that can mediate proliferation (cyclin D1 and c-Myc), inhibit apoptosis (survivin and TNF receptor associated factor 1), immunomodulation (chemokines and IL) and metastasis (intracellular adhesion molecule-1 and MMP-9) (73). Previously, EVO has been reported to promote hepatocellular carcinoma cell death by downregulating hypoxia-inducible factor- $1 \alpha$ (HIF-1 $\alpha$ ) expression (74). In addition, bone morphogenetic protein 9 has been found to mediate the anticancer effects of EVO by upregulation of HIF-1 $\alpha /$ p53 in colon cancer cells (75). Suppressing the Wnt and Notch signaling pathways, which serve crucial roles in cancer stem cell signaling, may also be involved in the anticancer activity of EVO (76-79).

\section{Pharmacokinetic characteristics}

Absorption and distribution. EVO is highly soluble in acetone, but barely soluble in ether or diluted alcohol and is insoluble in water, benzene or chloroform (80). Poor solubility and absorption means that EVO has low bioavailability (81). Shyr et al (26) reported that the bioavailability of EVO was only $0.1 \%$, with a maximum plasma concentration $\left(\mathrm{C}_{\max }\right)$ of $49.0 \pm 19.0 \mathrm{ng} / \mathrm{ml}$ following oral administration in rats (500 mg/kg) (26). A pharmacokinetic study of EVO previously performed in rabbits demonstrated that $5 \mathrm{~min}$ after intravenous administration of $4 \mathrm{mg} / \mathrm{kg} \mathrm{EVO}$, the plasma concentration of EVO was $877.0 \pm 96.6 \mathrm{ng} / \mathrm{ml}$ (82). Pharmacokinetic parameters simulated in beagle dog models demonstrated that the area under the curve (AUC) $0-24 \mathrm{~h}$ and the $\mathrm{C}_{\max }$ of EVO were $45.85 \pm 29.17 \mathrm{ng} \mathrm{h} / \mathrm{ml}$ and $30.94 \pm 12.16 \mathrm{ng} / \mathrm{ml}$, respectively, after administration with capsules encapsulated with $10 \mathrm{mg} / \mathrm{kg}$ EVO (83). The pharmacokinetics of EVO were also assessed following the oral administration of $\left[{ }^{3} \mathrm{H}\right]$ EVO in rats (84). The radioactivity levels in the plasma reached their maximum level within $1 \mathrm{~h}$ of oral administration, which declined in a biphasic manner, with half-times of 1.6 and $78.4 \mathrm{~h}$ (84). EVO 
Table I. Reported anti-cancer activities of evodiamine.

\begin{tabular}{|c|c|c|}
\hline System involved & Cancer cells & (Refs.) \\
\hline \multirow[t]{5}{*}{ Digestive system } & $\begin{array}{l}\text { Colon cell lines (lovo cells, colon cancer stem cell, HCT116 cells, colon 26-L5 } \\
\text { cells, colon COLO205 and HT-29 cells) }\end{array}$ & $\begin{array}{l}(19,39,49,75,76 \\
111-113)\end{array}$ \\
\hline & Gastric cancer cells (SGC7901 cells, BGC-823 cells) & $(46,50,63,77,114-116)$ \\
\hline & Oral cancer cells (MC3 cells, HSC4 cells, CAL-27 cell line) & $(117,118)$ \\
\hline & Pancreatic cancer cells (SW1990 cells, PANC-1 and SW1990 PC cell lines) & $(54,55,119)$ \\
\hline & $\begin{array}{l}\text { Hepatocellular carcinoma cells (HepG2, Bel-7402, QGY-7701 cells, Hepa1-6 } \\
\text { cells, SMMC-7721) }\end{array}$ & $\begin{array}{l}(21,47,48,71,74 \\
120-122)\end{array}$ \\
\hline \multirow[t]{2}{*}{$\begin{array}{l}\text { Respiratory } \\
\text { system }\end{array}$} & $\begin{array}{l}\text { Lung cancer cell lines (Lewis lung carcinoma, NCI-H446 and NCI-H1688 } \\
\text { cell lines, A549 cells, H1299 cells) }\end{array}$ & $(38,41,78,79,122-129)$ \\
\hline & Nasopharyngeal carcinoma cells (HONE1 and CNE1 cells) & $(69)$ \\
\hline $\begin{array}{l}\text { Circulatory } \\
\text { system }\end{array}$ & $\begin{array}{l}\text { Leukemic T-lymphocyte cells (CCRF-CEM cells, U937 cells, K562 cells, } \\
\text { THP-1 cells) }\end{array}$ & $(43,66,130,131)$ \\
\hline Nervous system & Glioblastoma cells (U87 cells, C6 glioma cells) & $(56,132-134)$ \\
\hline Motor system & Osteosarcoma cells (143B cells, MG63 Cells) & $(135-138)$ \\
\hline \multirow[t]{4}{*}{ Urinary system } & Prostate cancer cells (BPH-1 cells, PC-3 cells, DU145 cells, LNCaP cells) & $(9,59-61,139)$ \\
\hline & Bladder cancer cells ( $253 \mathrm{~J}$ cells and T24 cells) & $(140)$ \\
\hline & Urothelial cell carcinoma & $(141)$ \\
\hline & $\begin{array}{l}\text { Breast cancer cells (NCI/ADR-RES cells, MCF- } 7 \text { cells and ADR cells, } \\
\text { MDA-MB- } 231 \text { cells) }\end{array}$ & $(62,107,142-144)$ \\
\hline \multirow[t]{2}{*}{ Genital system } & Cervical cancer cells (HeLa cells) & $(44,45)$ \\
\hline & Ovarian cancer cells (A2780 cell lines, ES-2 cells, SKOV-3 cells) & $(20,145,146)$ \\
\hline Others & Melanoma cells (A375-S2 cells) & $(45,52,57,58,147-150)$ \\
\hline
\end{tabular}

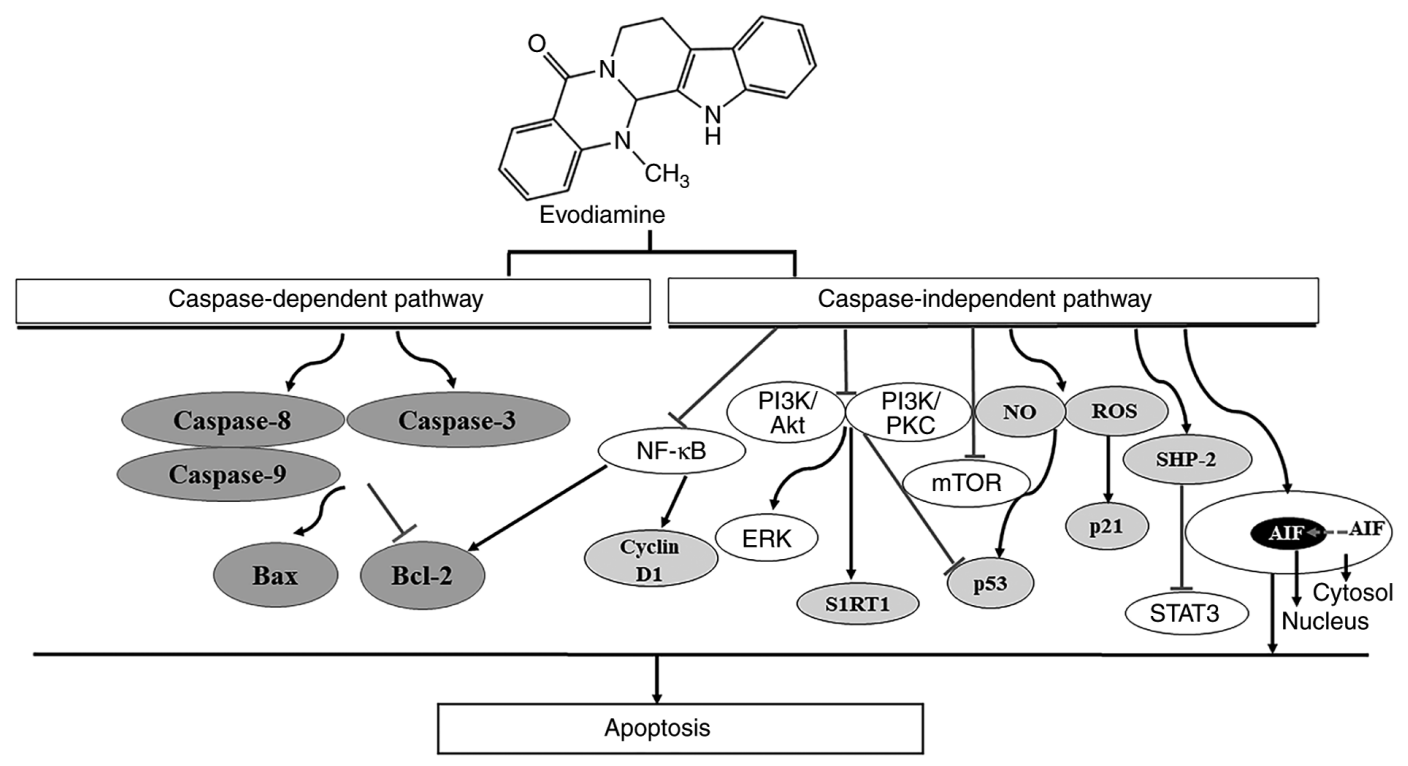

Figure 3. Potential underlying mechanism of EVO on the induction of tumor cell apoptosis. EVO can induce apoptosis through caspase-dependent pathways by activating either caspase- 8,9 or 3 , which decreases the expression of apoptosis suppressor Bcl-2 in tumor cells, whilst increasing the expression of the apoptosis inducer Bax. Activation of the caspase-independent apoptotic pathway is mediated by translocation of apoptosis-inducing factor into the nucleus. EVO exhibits apoptotic activity by inhibiting NF- $\mathrm{KB}$ activation, which inhibits the expression of downstream gene products cyclin D1 and Bcl-2. In addition, inactivation of the PI3K/AKT or PI3K/PKC signaling pathways decreases expression of the anti-apoptotic proteins SIRT1 and ERKs whilst increasing p53 expression. Generation of reactive oxygen species and nitric oxide also potentiates the function of p53 and p21, which can in turn mediate EVO-induced apoptosis. Arrows represent stimulatory effects, whilst dotted arrows represent translocation and T-lines represent inhibitory effects. EVO, evodiamine; PKC, protein kinase C; SIRT1, sirtuin 1.

has also been reported to reach a maximum plasma concentration in rat $3.38 \mathrm{~h}\left(\mathrm{~T}_{\max }\right)$ after oral administration (35). EVO is predominantly distributed in the liver, kidney, heart and lungs, where 19 and $63 \%$ of orally administered EVO is eliminated 


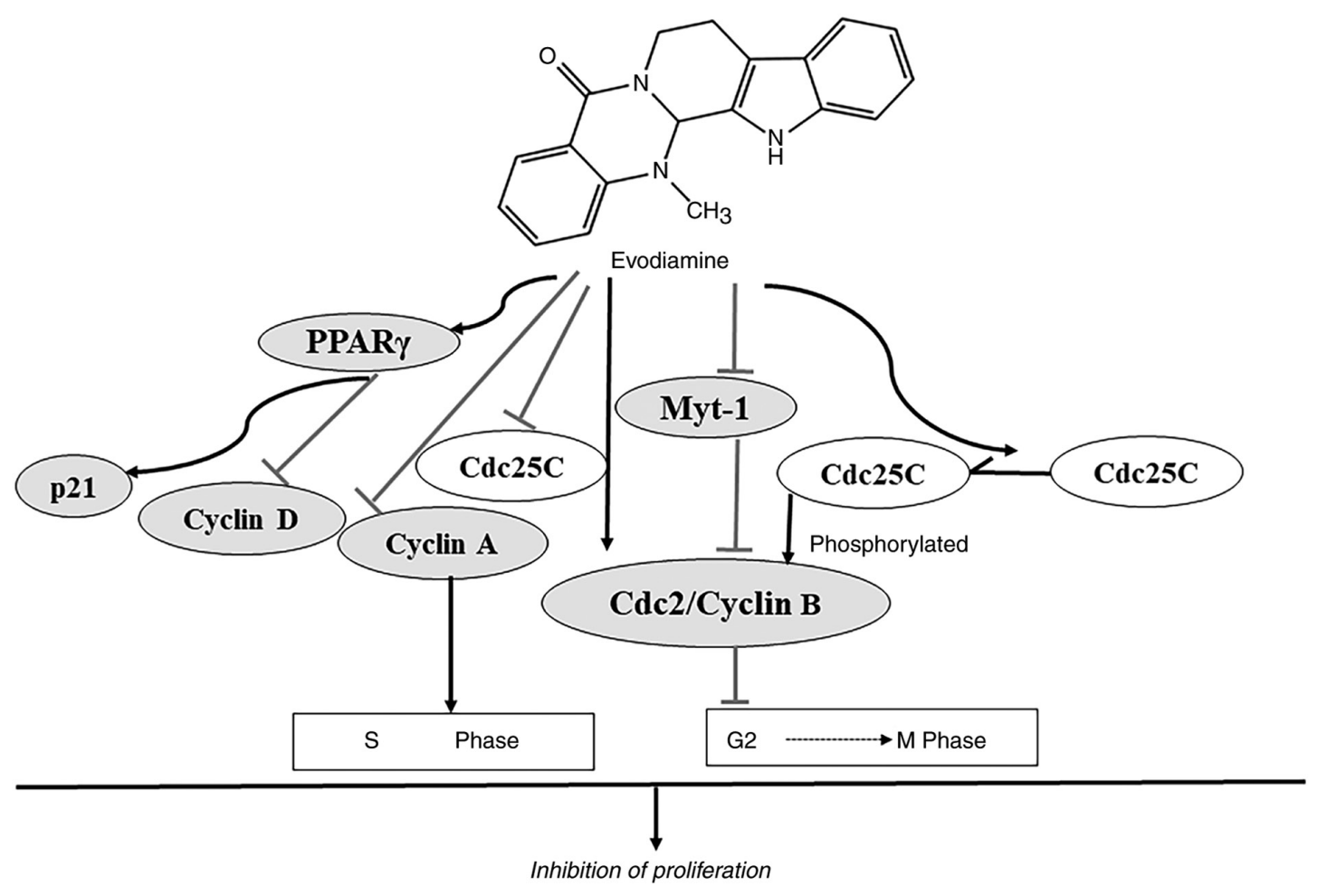

Figure 4. Potential underlying mechanism of EVO on the inhibition of proliferation and cell cycle progression. EVO suppresses cell proliferation by blocking cell cycle progression at $\mathrm{G}_{2} / \mathrm{M}$ phase by concurrently inhibiting Myt-1 and activating Cdc25C phosphatase, which significantly increases the activation of the Cdc2/cyclin B complex. In addition, EVO downregulates cyclin A expression, which induces S-phase arrest in cancer cells. EVO can also inhibit cancer cell proliferation by activating the PPAR $\gamma$ signaling pathway by downregulating cyclin D1 whilst upregulating the expression of the cyclin-dependent kinase inhibitor p21. Arrows represent stimulatory effects and T-lines represent inhibitory effects. EVO, evodiamine; Cdc, cell division cycle; PPAR $\gamma$, peroxisome proliferators-activated receptor $\gamma$; myt-1, membrane-associated tyrosine- and threonine-specific cdc2-inhibitory kinase.

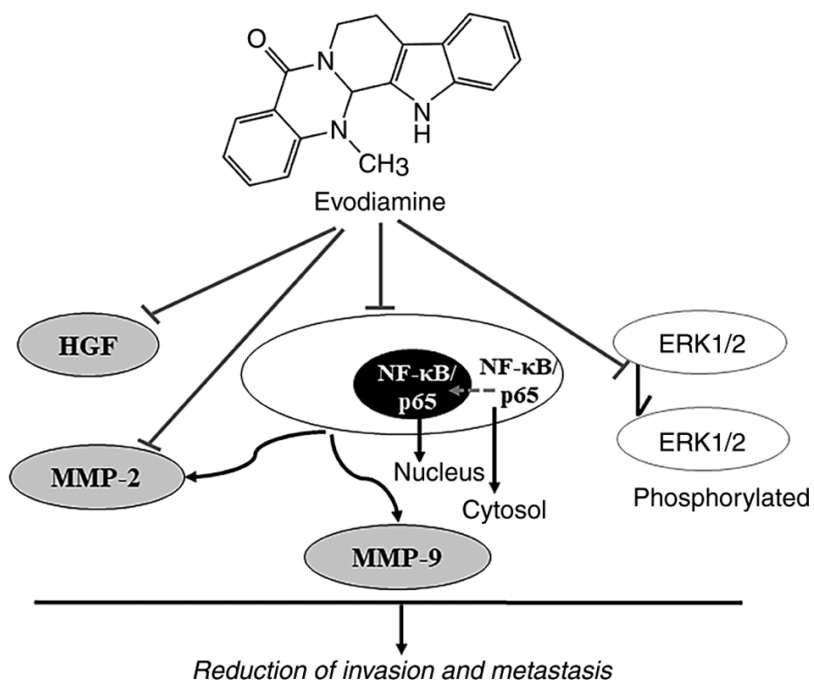

Figure 5. Key roles of EVO in inhibiting the invasion and metastasis of cancer cells. EVO inhibits the invasion and metastasis of tumor cells by suppressing HGF activity, suppressing MMP-2 expression or attenuating the activation of ERK1/2. Furthermore, EVO inhibits the migration and invasion of cancer cells by decreasing MMP-9 expression by suppressing NF- $\mathrm{kB} / \mathrm{p} 65$ nuclear translocation and NF- $\mathrm{kB} / \mathrm{p} 65$ acetylation. Arrows represent stimulatory effects; dotted arrows indicates translocation; half arrows represent phosphorylation and T-lines indicate inhibitory effects. EVO, evodiamine; HGF, hepatocyte growth factor.

in the urine and bile after $24 \mathrm{~h}$, respectively (84). The pharmacokinetic process following the intravenous administration of
EVO was characterized by a two-compartment model, which appears to be a biphasic phenomenon with a rapid distribution phase followed by a slower elimination phase (85). The absorption of EVO by rats with headaches induced by Nitroglycerin was significantly higher compared with that in the healthy group (86). Compared with the crude drug, the $\mathrm{Wu}-\mathrm{Zhu}-\mathrm{Yu}$ extract appeared to increase the bioavailability of EVO, with increased purities (16-80\%), suggesting that some ingredients in the $\mathrm{Wu}-\mathrm{Zhu}-\mathrm{Yu}$ extract may promote the efficacy of EVO in vivo (81). At present, the low bioavailability of EVO has been confirmed in different animal models. These differences in the pharmacokinetic parameters may be due to the diversity of measurements and estimation methods. However, further studies are required to understand the distribution in the body and excretion of EVO.

Metabolism. Komatsu et al (84) demonstrated that $\left[{ }^{3} \mathrm{H}\right] \mathrm{EVO}$ can be converted into metabolites in rats. A previous study demonstrated that EVO is readily susceptible to metabolism, forming hydroxylation metabolites, which exhibit potent cytotoxicity compared with that mediated by EVO (35). Furthermore, another study suggested that the 3-alkylindole moiety on EVO is a potential toxicophore in P450-mediated dehydrogenation reactions (34). Therefore, the metabolic bioactivation of EVO may be closely associated with its pharmacological effects and toxicity (35).

Aromatic, aliphatic hydroxylation, N-demethylation, oxygenation, dehydrogenation, glucuronidation and GSH conjugation are involved in the metabolic pathways of EVO, 
where a methyl group in position 14 of EVO may contribute to its metabolic properties $(87,88)$. In vitro incubation of $\mathrm{EVO}$ with human and rat liver microsomes, in the presence of NADPH, resulted in the formation of four mono-hydroxylated metabolites and one N-demethylated metabolite (87). Cytochrome (CYP)3A4, CYP2C9 and CYP1A2 have been identified to be the main CYP isoforms involved in the metabolism of EVO in human liver microsomes (87). Several GSH conjugates of EVO were also found after the addition of sulfhydryl nucleophiles to EVO (34). Recently, a total of 12 phase I metabolites of EVO were found in human liver microsomes, whilst 12 phase I metabolites and seven phase II conjugated metabolites were identified and quantified in human hepatocytes (88). In vivo experiments demonstrated that the metabolites of EVO, 10-hydroxyevodiamine and 18-hydroxyevodiamine, were rapidly converted from EVO within $0.167 \mathrm{~h}$ after oral administration in rats, which further conjugated with glucuronide to form 10-hydroxyevodiamine-glucuronide and 18-hydroxy-evodiamine-glucuronide (35). A cocktail method was used to investigate the metabolism of EVO involving the P450 family of metabolizing enzymes (89). The results demonstrated that EVO inhibited the activities of the metabolizing enzymes, CYP1A2, CYP2C9 and CYP2D6, which increases the half-life $\left(\mathrm{t}_{1 / 2}\right), \mathrm{C}_{\max }$ and $\mathrm{AUC}_{(0-\infty)}$, whilst decreasing the clearance of the corresponding enzymatic substrates (89).

\section{Approaches to improve the oral bioavailability}

The metabolism of low-solubility natural medicines partly depend on drug-drug interactions and the delivery systems (33). Appropriate drug delivery systems can contribute to increased absorption, improved bioavailability, prolonged residence time and minimized side effects of low-solubility natural medicines (33).

The solid dispersion technique has been used to enhance the dissolution rate and solubility of EVO. A previous study demonstrated that solid dispersion of EVO in hard capsules has a greater absorption rate compared with that of enriched samples of EVO in physical hard capsules (90). Following oral administration of EVO $(57.5 \mathrm{mg})$, the $\mathrm{C}_{\max }$ of solid dispersion $(27.85 \pm 13.78 \mathrm{mg} / \mathrm{l})$ was notably higher compared with that of physical mixtures $(10.48 \pm 7.28 \mathrm{mg} / \mathrm{l})$. Notably, solid dispersion also contributed to an advanced $\mathrm{T}_{\max }$ and a shorter $\mathrm{T}_{1 / 2}$ of EVO in beagle dogs (90). Phospholipids also possess the potential for improving oral bioavailability and biological efficacy of drugs with low aqueous solubility, by forming noncovalently bonded drug-phospholipid complexes $(91,92)$. Tan et al (91) previously designed a novel EVO-phospholipid complex (EPLC), with a higher bioavailability than free EVO. Compared with free EVO, the relative bioavailability of EPLC was significantly increased to $218.82 \%$ (91).

Cytotoxic drug-carrying nano-carriers are a viable strategy for enhancing cancer cell cytotoxicity and minimizing side effects. Nano-emulsion, which includes lipid nano-emulsion, inclusion complexes, nanoparticles and noisomes, is a vital component of nano-carriers (33). A novel type of water-in-oil nano-emulsion containing EVO-phospholipid nanocomplexes (NEEPN) was considered to be a good carrier for the oral delivery of EVO due to its favorable in vivo kinetic characteristics in rat (93). It markedly enhanced the oral bioavailability of
EVO to $630.35 \%$ by increasing gastrointestinal absorption and the effective permeability of NEEPN in the colon was increased 8.64-fold compared with free EVO (93). Woody oil-based emulsive nanosystem was also used to increase the sensitivity of lung cancer cells to EVO $(93,94)$. In addition, the bioavailability of EVO was increases following formation of inclusion complexes $(95,96)$. EVO hydroxypropyl- $\beta$-cyclodextrin complexes have been reported to improve the oral bioavailability of EVO by 2.56 -fold, increase the $\mathrm{C}_{\max }$ and extend the $\mathrm{T}_{\max }$ by 1.57- and 1.01-folds, respectively (95).

Recently, mesoporous silica nanoparticles (MSNs) have become an attractive type of carrier for hydrophobic and hydrophilic agents due to their site-specific functionalization prominent biocompatibility and large loading surface areas $(97,98)$. EVO is loaded with berberine using a novel temperature- and $\mathrm{pH}$-responsive dual drug delivery platform-coated MSN to improve efficacy and biocompatibility in the low $\mathrm{pH}$ and high temperature microenvironment of the tumor (99). This MSN-loaded drug pair (EVO and berberine) not only possessed optimal synergistic therapeutic effects in vitro (cytotoxicity, cell migration, invasion and angiogenesis) and in vivo (growth of tumor grafts in mice), but also exhibited low systemic toxicity (99). In another study, a delivery system based on poly (lactic-co-glycolic acid) nanoparticles was established to deliver EVO to overcome its drawbacks of limited solubility and low bioavailability (100). It persistently controlled the release of EVO for $>180 \mathrm{~h}$, suggesting that it can became a potential agent for improving anticancer efficacy of EVO in breast cancer therapy (100). In addition, EGFR-targeting EVO-encapsulated poly (amino acid) nanoparticles have been developed as a new class of nanotherapeutics (101). These nanoparticles exert significantly improved cytotoxicity on colon cancer cells, resulting in the downregulation of EGFR and extension of the tumor-bearing survival duration (101). However, the application of niosomes for the delivery of EVO is yet to be investigated.

Novel carriers, micelles and microspheres have been applied to load natural medicine with low solubility and high permeability. Polymeric micelles, including paclitaxel micelles (102) and tanshinone IIA micelles $(103,104)$, exhibit high capacity for drug loading and have the ability to improve the bioavailability of drugs (4.33-fold higher than free paclitaxel and 5.60-fold higher than free tanshinone IIA). Chitosan microspheres are biocompatible and readily biodegradable, which can enhance the absolute bioavailability of paclitaxel by 1.52 -fold (105) whilst increasing the oral bioavailability of capsaicin by 1.53 -fold (106). However, these drug delivery systems are yet to be applied for the bioavailability of EVO.

\section{Conclusions and prospects}

TCM is considered a promising source of potential anticancer agents and novel adjuvant therapies to improve the efficacy of chemotherapy with little to no side effects. A previous study has demonstrated that EVO can enhance doxorubicin sensitivity in doxorubicin-resistant breast cancer cells by synchronously affecting apoptosis and survival signaling transduction pathways, thereby enhancing the apoptotic action of doxorubicin (107). In addition, combined treatment of erlotinib with EVO, an oral epidermal growth factor 
receptor tyrosine kinase inhibitor, successfully inhibited cell proliferation and survival in erlotinib-resistant wild-type EGFR non-small cell lung cancer cells (108). These favorable anti-cancer properties of EVO would contribute to the killing of resistant cancer cells in the clinic with minimal toxicity. Previous studies on the antitumor mechanisms of EVO have suggested an exciting future for the pursuit of anticancer therapies. Although EVO is currently used in the clinic as a TCM to treat headaches, abdominal pain, vomiting and colds in Southeast Asia $(109,110)$, it has not been clinically approved as an anticancer agent. Considering the therapeutic potential of EVO for antitumor treatment, an approach to improve the oral bioavailability and enhance its pharmacological effects would prove beneficial, thus minimizing the possible adverse effects due to overdosing.

Since advanced delivery systems have been proposed, the oral bioavailability of EVO can be notably improved by increasing absorption whilst avoiding first-pass metabolism. Since a substantial signaling network involved in apoptosis or proliferation inside the cell can be stimulated by EVO, exploring the possible targets of EVO on cell the membrane and any ligand-receptor interactions would be a potential means of developing novel transportable compounds to address the defect in absorption. The inhibitory effects of EVO on various CYP enzymes may decrease the biotransformation of medicines primarily dependent on these pathways. The inhibition of metabolic enzymes and resultant promotion of drug potency by EVO will facilitate the investigation of potential drug-drug or herb-drug interactions and evaluation of their clinical safety.

Previous studies have focused on the anticancer activity and underlying mechanisms of EVO. The present review discussed the advances in research investigating the anticancer effects of EVO over the past two decades, highlighting the pharmacokinetics and practicality of using novel loading carriers to promote the absorption of EVO and enhance the bioavailability of drugs with low solubility. It is hoped that all of this will contribute to the clinical application of EVO and T. ruticarpum.

\section{Acknowledgements}

Not applicable.

\section{Funding}

The present study was supported by the Basic Scientific Research Project of Guangxi Academy of Agricultural Sciences (grant no. 2021YT144).

\section{Availability of data and materials}

Not applicable.

\section{Authors' contributions}

CL designed and drafted the manuscript, JA collected the information and prepared the figures. ER collected the information and prepared Table I. JL and CF supervised and revised the manuscript. XLi and XLu drew the chemical structure and prepared Fig. 2. All authors have read and approved the final manuscript.

\section{Ethics approval and consent to participate}

Not applicable.

\section{Patient consent for publication}

Not applicable.

\section{Competing interests}

The authors declare that they have no competing interests.

\section{References}

1. Zhang L, Feng YL, Wang YS and Yang SL: Modern research status on Evodia rutaecarpa. J Jiangxi Univ Tradit Chin Med 22: $5,2010$.

2. Nam EY, Kim SA, Kim H, Kim SH, Han JH, Lee JH and Kim DI: Akt activation by Evodiae fructus extract protects ovary against 4-vinylcyclohexene diepoxide-induced ovotoxicity. J Ethnopharmacol 194: 733-739, 2016

3. Sui H, Liu X, Jin BH, Pan SF, Zhou LH, Yu NA, Wu J, Cai JF, Fan ZZ, Zhu HR and Li Q: Zuo Jin Wan, a traditional Chinese herbal formula, reverses P-gp-mediated MDR in vitro and in vivo. Evid Based Complement Alternat Med 2013: 957078, 2013.

4. Pan J, Xu Y, Song H, Zhou X, Yao Z and Ji G: Extracts of Zuo Jin Wan, a traditional Chinese medicine, phenocopies 5 -HTR1D antagonist in attenuating Wnt/ $\beta$-catenin signaling in colorectal cancer cells. BMC Complement Altern Med 17: 506, 2017.

5. Tang QF, Ji Q, Qiu YY, Cao AL, Chi YF, Liang B, Peng W and Yin PH: Synergistic effect of Zuo Jin Wan on DDP-induced apoptosis in human gastric cancer SGC-7901/DDP cells. Evid Based Complement Alternat Med 2014: 724764, 2014.

6. Guan X, Zheng X, Vong CT, Zhao J, Xiao J, Wang Y and Zhong Z: Combined effects of berberine and evodiamine on colorectal cancer cells and cardiomyocytes in vitro. Eur J Pharmacol 875: 173031,2020

7. Chou ST, Hsiang CY, Lo HY, Huang HF, Lai MT, Hsieh CL, Chiang SY and Ho TY: Exploration of anti-cancer effects and mechanisms of Zuo-Jin-Wan and its alkaloid components in vitro and in orthotopic HepG2 xenograft immunocompetent mice. BMC Complement Altern Med 17: 121, 2017.

8. Bae JR, Park WH, Suh DH, No JH, Kim YB and Kim K: Role of limonin in anticancer effects of evodia rutaecarpa on ovarian cancer cells. BMC Complement Med Ther 20: 94, 2020.

9. Park E, Lee MY, Seo CS, Jang JH, Kim YU and Shin HK: Ethanol extract of evodia rutaecarpa attenuates cell growth through caspase-dependent apoptosis in benign prostatic hyperplasia-1 cells. Nutrients 10: 523, 2018.

10. Gong X, Zhou X, Cai Z, Zhang J and Zhou W: Studies on chemical constituents of Evodia rutaecarpa. Zhongguo Zhong Yao Za Zhi 34: 177-179, 2009 (In Chinese).

11. Kim D, Lee YH, Park SH, Lee MJ, Kim MJ, Jang HS, Lee JM, Lee HY, Han BS, Son WC, et al: Subchronic oral toxicity of evodia fruit powder in rats. J Ethnopharmacol 151: 1072-1078, 2014.

12. Hu X, Li D, Chu C, Li X, Wang X, Jia Y, Hua H and Xu F: Antiproliferative effects of alkaloid evodiamine and its derivatives. Int J Mol Sci 19: 3403, 2018.

13. Wu JY, Chang MC, Chen CS, Lin HC, Tsai HP, Yang CC, Yang $\mathrm{CH}$ and Lin CM: Topoisomerase I inhibitor evodiamine acts as an antibacterial agent against drug-resistant Klebsiella pneumoniae. Planta Med 79: 27-29, 2013.

14. Peng J and Li YJ: The vanilloid receptor TRPV1: Role in cardiovascular and gastrointestinal protection. Eur J Pharmacol 627: 1-7, 2010.

15. Zhao Z, Gong S, Wang S and Ma C: Effect and mechanism of evodiamine against ethanol-induced gastric ulcer in mice by suppressing Rho/NF- $\mathrm{B}$ pathway. Int Immunopharmacol 28 : 588-595, 2015. 
16. Yu H, Jin H, Gong W, Wang Z and Liang H: Pharmacological actions of multi-target-directed evodiamine. Molecules 18: 1826-1843, 2013

17. Yuan SM, Gao K, Wang DM, Quan XZ, Liu JN, Ma CM, Qin C and Zhang LF: Evodiamine improves congnitive abilities in SAMP8 and APP(swe)/PS1( $\triangle \mathrm{E} 9)$ transgenic mouse models of Alzheimer's disease. Acta Pharmacol Sin 32: 295-302, 2011.

18. Pan X, Hartley JM, Hartley JA, White KN, Wang Z and Bligh SW: Evodiamine, a dual catalytic inhibitor of type I and II topoisomerases, exhibits enhanced inhibition against camptothecin resistant cells. Phytomedicine 19: 618-624, 2012.

19. Huang J, Chen ZH, Ren CM, Wang DX, Yuan SX, Wu QX, Chen QZ, Zeng YH, Shao Y, Li Y, et al: Antiproliferation effect of evodiamine in human colon cancer cells is associated with IGF-1/HIF-1 $\alpha$ downregulation. Oncol Rep 34: 3203-3211, 2015.

20. Zhong ZF, Tan W, Wang SP, Qiang WA and Wang YT: Anti-proliferative activity and cell cycle arrest induced by evodiamine on paclitaxel-sensitive and -resistant human ovarian cancer cells. Sci Rep 5: 16415, 2015.

21. Yang J, Cai X, Lu W, Hu C, Xu X, Yu Q and Cao P: Evodiamine inhibits STAT3 signaling by inducing phosphatase shatterproof 1 in hepatocellular carcinoma cells. Cancer Lett 328: 243-251, 2013.

22. Wei J, Ching LC, Zhao JF, Shyue SK, Lee HF, Kou YR and Lee TS: Essential role of transient receptor potential vanilloid type 1 in evodiamine-mediated protection against atherosclerosis. Acta Physiol (Oxf) 207: 299-307, 2013.

23. Wanner SP, Garami A, Pakai E, Oliveira DL, Gavva NR, Coimbra CC and Romanovsky AA: Aging reverses the role of the transient receptor potential vanilloid-1 channel in systemic inflammation from anti-inflammatory to proinflammatory. Cell Cycle 11: 343-349, 2012.

24. Mezrich JD, Nguyen LP, Kennedy G, Nukaya M, Fechner JH, Zhang X, Xing Y and Bradfield CA: SU5416, a VEGF receptor inhibitor and ligand of the AHR, represents a new alternative for immunomodulation. PLoS One 7: e44547, 2012.

25. O'Donnell EF, Kopparapu PR, Koch DC, Jang HS, Phillips JL, Tanguay RL, Kerkvliet NI and Kolluri SK: The aryl hydrocarbon receptor mediates leflunomide-induced growth inhibition of melanoma cells. PLoS One 7: e40926, 2012.

26. Shyr MH, Lin LC, Lin TY and Acta TH: Determination and pharmacokinetics of evodiamine in the plasma and feces of conscious rats. Anal Chim Acta 558: 16-21, 2006.

27. Lefrak EA, Pitha J, Rosenheim S and Gottlieb JA: A clinicopathologic analysis of adriamycin cardiotoxicity. Cancer 32 302-314, 1973.

28. Olson RD, Mushlin PS, Brenner DE, Fleischer S, Cusack BJ, Chang BK and Boucek RJ Jr: Doxorubicin cardiotoxicity may be caused by its metabolite, doxorubicinol. Proc Natl Acad Sci USA 85: 3585-3589, 1988.

29. Stewart DJ, Grewaal D, Green RM, Mikhael N, Goel R, Montpetit VA and Redmond MD: Concentrations of doxorubicin and its metabolites in human autopsy heart and other tissues. Anticancer Res 13: 1945-1952, 1993

30. Yang W, Ma L, Li S, Cui K, Lei L and Ye Z: Evaluation of the cardiotoxicity of evodiamine in vitro and in vivo. Molecules 22: 943, 2017

31. Huang W, Zhao Y and Sun R: Comparative study on acute toxicity of different components of Evodia rutaecarpa in mice. Zhongguo Yao Wu Jing Jie 7: 129-134, 2010.

32. Li F, Dong YZ, Zhang D, Zhang XM, Lin ZJ and Zhang B Molecular mechanisms involved in drug-induced liver injury caused by urate-lowering Chinese herbs: A network pharmacology study and biology experiments. PLoS One 14: e0216948, 2019.

33. Yan S, Liu Y, Feng J, Zhao H, Yu Z, Zhao J, Li Y and Zhang J: Difference and alteration in pharmacokinetic and metabolic characteristics of low-solubility natural medicines. Drug Metab Rev 50: 140-160, 2018.

34. Wen B, Roongta V, Liu L and Moore DJ: Metabolic activation of the indoloquinazoline alkaloids evodiamine and rutaecarpine by human liver microsomes: Dehydrogenation and inactivation of cytochrome P450 3A4. Drug Metab Dispos 42: 1044-1054, 2014.

35. Wang C, Yue F, Ai G and Yang J: Simultaneous determination of evodiamine and its four metabolites in rat plasma by LC-MS/MS and its application to a pharmacokinetic study. Biomed Chromatogr 32: e4219, 2018.

36. Li L, Liu R, Ye M, Hu X, Qiao W, Bi K and Guo D: Microbial metabolism of evodiamine by penicillium janthinellum and its application for metabolite identification in rat urine. Enzyme Microb Technol 39: 561-567, 2006.
37. Jiang $\mathrm{J}$ and $\mathrm{Hu} \mathrm{C}$ : Evodiamine: A novel anti-cancer alkaloid from evodia rutaecarpa. Molecules 14: 1852-1859, 2009.

38. Ogasawara M, Matsunaga T, Takahashi S, Saiki I and Suzuki H Anti-invasive and metastatic activities of evodiamine. Biol Pharm Bull 25: 1491-1493, 2002.

39. Chien CC, Wu MS, Shen SC, Ko CH, Chen CH, Yang LL and Chen YC: Activation of JNK contributes to evodiamine-induced apoptosis and $\mathrm{G} 2 / \mathrm{M}$ arrest in human colorectal carcinoma cells: A structure-activity study of evodiamine. PLoS One 9: e99729, 2014.

40. Rao L and White E: Bcl-2 and the ICE family of apoptotic regulators: Making a connection. Curr Opin Genet Dev 7: 52-58, 1997.

41. Zou Y, Qin X, Xiong H, Zhu F, Chen T and Wu H: Apoptosis of human non-small-cell lung cancer A549 cells triggered by evodiamine through MTDH-dependent signaling pathway. Tumour Biol 36: 5187-5193, 2015.

42. Zhu LH, Bi W, Liu XD, Li JF, Wu YY, Du BY and Tan YH: Induction of apoptosis by evodiamine involves both activation of mitotic arrest and mitotic slippage. Oncol Rep 26: 1447-1455, 2011.

43. Lee TJ, Kim EJ, Kim S, Jung EM, Park JW, Jeong SH, Park SE, Yoo YH and Kwon TK: Caspase-dependent and caspase-independent apoptosis induced by evodiamine in human leukemic U937 cells. Mol Cancer Ther 5: 2398-2407, 2006.

44. Fei XF, Wang BX, Li TJ, Tashiro S, Minami M, Xing DJ and Ikejima T: Evodiamine, a constituent of Evodiae fructus, induces anti-proliferating effects in tumor cells. Cancer Sci 94: 92-98, 2003.

45. Zhang Y, Wu LJ, Tashiro S, Onodera S and Ikejima T: Intracellular regulation of evodiamine-induced A375-S2 cell death. Biol Pharm Bull 26: 1543-1547, 2003.

46. Liu X, Yang L, Bi Y, Wang LH and Huang H: Effect of evodiamine in inducing apoptosis of gastric cancer SGC-7901 cells through mTOR signal pathway. Zhongguo Zhong Yao Za Zhi 40: 3262-3266, 2015 (In Chinese).

47. Yang F, Shi L, Liang T, Ji L, Zhang G, Shen Y, Zhu F and Xu L: Anti-tumor effect of evodiamine by inducing Akt-mediated apoptosis in hepatocellular carcinoma. Biochem Biophys Res Commun 485: 54-61, 2017.

48. Guo XX, Li XP, Zhou P, Li DY, Lyu XT, Chen Y, Lyu YW, Tian K, Yuan DZ, Ran JH, et al: Evodiamine induces apoptosis in SMMC-7721 and HepG2 cells by suppressing NOD1 signal pathway. Int J Mol Sci 19: 3419, 2018.

49. Zhang C, Fan X, Xu X, Yang X, Wang X and Liang HP: Evodiamine induces caspase-dependent apoptosis and $\mathrm{S}$ phase arrest in human colon lovo cells. Anticancer Drugs 21: 766-776, 2010.

50. Yang L, Liu X, Wu D, Zhang M, Ran G, Bi Y and Huang H Growth inhibition and induction of apoptosis in SGC-7901 human gastric cancer cells by evodiamine. Mol Med Rep 9: 1147-1152, 2014.

51. Zhu B, Zhao L, Liu Y, Jin Y, Feng J, Zhao F, Sun J, Geng R and Wei Y: Induction of phosphatase shatterproof 2 by evodiamine suppresses the proliferation and invasion of human cholangiocarcinoma. Int J Biochem Cell Biol 108: 98-110, 2019.

52. Yang J, Wu LJ, Tashino S, Onodera S and Ikejima T: Critical roles of reactive oxygen species in mitochondrial permeability transition in mediating evodiamine-induced human melanoma A375-S2 cell apoptosis. Free Radic Res 41: 1099-1108, 2007.

53. Yang J, Wu LJ, Tashino S, Onodera S and Ikejima T: Reactive oxygen species and nitric oxide regulate mitochondria-dependent apoptosis and autophagy in evodiamine-treated human cervix carcinoma HeLa cells. Free Radic Res 42: 492-504, 2008.

54. Wei WT, Chen H, Wang ZH, Ni ZL, Liu HB, Tong HF, Guo HC, Liu DL and Lin SZ: Enhanced antitumor efficacy of gemcitabine by evodiamine on pancreatic cancer via regulating PI3K/Akt pathway. Int J Biol Sci 8: 1-14, 2012.

55. Hong Z, Wang Z, Zhou B, Wang J, Tong H, Liao Y, Zheng P, Jamshed MB, Zhang Q and Chen H: Effects of evodiamine on $\mathrm{PI} 3 \mathrm{~K} / \mathrm{Akt}$ and MAPK/ERK signaling pathways in pancreatic cancer cells. Int J Oncol 56: 783-793, 2020.

56. Wang R, Deng D, Shao N, Xu Y, Xue L, Peng Y, Liu Y and Zhi F: Evodiamine activates cellular apoptosis through suppressing PI3K/AKT and activating MAPK in glioma. Onco Targets Ther 11: 1183-1192, 2018

57. Wang C, Li S and Wang MW: Evodiamine-induced human melanoma A375-S2 cell death was mediated by PI3K/Akt/caspase and Fas-L/NF-kappaB signaling pathways and augmented by ubiquitin-proteasome inhibition. Toxicol In Vitro 24: 898-904, 2010 . 
58. Wang C, Wang MW, Tashiro S, Onodera S and Ikejima T: Roles of SIRT1 and phosphoinositide 3-OH kinase/protein kinase C pathways in evodiamine-induced human melanoma A375-S2 cell death. J Pharmacol Sci 97: 494-500, 2005.

59. Huang DM, Guh JH, Huang YT, Chueh SC, Chiang PC and Teng CM: Induction of mitotic arrest and apoptosis in human prostate cancer pc-3 cells by evodiamine. J Urol 173: 256-261, 2005.

60. Kan SF, Yu CH, Pu HF, Hsu JM, Chen MJ and Wang PS Anti-proliferative effects of evodiamine on human prostate cancer cell lines DU145 and PC3. J Cell Biochem 101: 44-56, 2007.

61. Kan SF, Huang WJ, Lin LC and Wang PS: Inhibitory effects of evodiamine on the growth of human prostate cancer cell line LNCaP. Int J Cancer 110: 641-651, 2004.

62. Liao CH, Pan SL, Guh JH, Chang YL, Pai HC, Lin CH and Teng CM: Antitumor mechanism of evodiamine, a constituent from Chinese herb Evodiae fructus, in human multiple-drug resistant breast cancer NCI/ADR-RES cells in vitro and in vivo. Carcinogenesis 26: 968-975, 2005.

63. Rasul A, Yu B, Zhong L, Khan M, Yang H and Ma T: Cytotoxic effect of evodiamine in SGC-7901 human gastric adenocarcinoma cells via simultaneous induction of apoptosis and autophagy. Oncol Rep 27: 1481-1487, 2012.

64. Graves PR, Yu L, Schwarz JK, Gales J, Sausville EA, O'Connor PM and Piwnica-Worms H: The Chk1 protein kinase and the $\mathrm{Cdc} 25 \mathrm{C}$ regulatory pathways are targets of the anticancer agent UCN-01. J Biol Chem 275: 5600-5605, 2000.

65. Devault A, Martinez AM, Fesquet D, Labbé JC, Morin N, Tassan JP, Nigg EA, Cavadore JC and Dorée M: MAT1 ('menage à trois') a new RING finger protein subunit stabilizing cyclin H-cdk7 complexes in starfish and Xenopus CAK. EMBO J 14: 5027-5036, 1995

66. Sun C, Zhang G, Luan S, Luan C, Shao H, Dong F and Liu X Evodiamine inhibits the proliferation of leukemia cell line K562 by regulating peroxisome proliferators-activated receptor gamma (PPAR $\gamma$ ) pathway. J Recept Signal Transduct Res 36: 422-428, 2016

67. Moosavi F, Giovannetti E, Saso L and Firuzi O: HGF/MET pathway aberrations as diagnostic, prognostic, and predictive biomarkers in human cancers. Crit Rev Clin Lab Sci 56: 533-566, 2019.

68. Ogasawara M and Suzuki H: Inhibition by evodiamine of hepatocyte growth factor-induced invasion and migration of tumor cells. Biol Pharm Bull 27: 578-582, 2004.

69. Peng X, Zhang Q, Zeng Y, Li J, Wang L and Ai P: Evodiamine inhibits the migration and invasion of nasopharyngeal carcinoma cells in vitro via repressing MMP-2 expression. Cancer Chemother Pharmacol 76: 1173-1184, 2015.

70. Zhou P, Li XP, Jiang R, Chen Y, Lv XT, Guo XX, Tian K, Yuan DZ, Lv YW, Ran JH, et al: Evodiamine inhibits migration and invasion by Sirtl-mediated post-translational modulations in colorectal cancer. Anticancer Drugs 30: 611-617, 2019.

71. Shi L, Yang F, Luo F, Liu Y, Zhang F, Zou M and Liu Q: Evodiamine exerts anti-tumor effects against hepatocellular carcinoma through inhibiting $\beta$-catenin-mediated angiogenesis. Tumour Biol 37: 12791-12803, 2016.

72. Shyu KG, Lin S, Lee CC, Chen E, Lin LC, Wang BW and Tsai SC: Evodiamine inhibits in vitro angiogenesis: Implication for antitumorgenicity. Life Sci 78: 2234-2243, 2006.

73. Takada Y, Kobayashi Y and Aggarwal BB: Evodiamine abolishes constitutive and inducible NF-kappaB activation by inhibiting IkappaBalpha kinase activation, thereby suppressing NF-kappaB-regulated antiapoptotic and metastatic gene expression, up-regulating apoptosis, and inhibiting invasion. J Biol Chem 280: 17203-17212, 2005 .

74. Li YL, Zhang NY, Hu X, Chen JL, Rao MJ, Wu LW, Li QY, Zhang B, Yan W and Zhang C: Evodiamine induces apoptosis and promotes hepatocellular carcinoma cell death induced by vorinostat via downregulating HIF-1 $\alpha$ under hypoxia. Biochem Biophys Res Commun 498: 481-486, 2018.

75. Li FS, Huang J, Cui MZ, Zeng JR, Li PP, Li L, Deng Y, Hu Y, He BC and Shu DZ: BMP9 mediates the anticancer activity of evodiamine through HIF-1 $\alpha /$ p53 in human colon cancer cells. Oncol Rep 43: 415-426, 2020.

76. Kim H, Yu Y, Choi S, Lee H, Yu J, Lee JH and Kim WY: Evodiamine eliminates colon cancer stem cells via suppressing notch and Wnt signaling. Molecules 24: 4520, 2019.

77. Wen Z,Feng S, Wei L, Wang Z, Hong D and Wang Q: Evodiamine, a novel inhibitor of the Wnt pathway, inhibits the self-renewal of gastric cancer stem cells. Int J Mol Med 36: 1657-1663, 2015.
78. Yang X, Zhang Y, Huang Y, Wang Y, Qi X, Su T and Lu L: Evodiamine suppresses Notch3 signaling in lung tumorigenesis via direct binding to $\gamma$-secretases. Phytomedicine 68: 153176, 2020

79. Su T, Yang X, Deng JH, Huang QJ, Huang SC, Zhang YM, Zheng HM, Wang Y, Lu LL and Liu ZQ: Evodiamine, a novel NOTCH3 methylation stimulator, significantly suppresses lung carcinogenesis in vitro and in vivo. Front Pharmacol 9: 434, 2018

80. Gai L, Rao GX, Song CQ and Hu ZB: Studies on the chemical constituents of evodia rutaecarpa (Juss.) Benth. var. officinalis (Dode) Huang. Yao Xue Xue Bao 36: 743-745, 2001 (In Chinese)

81. Xu S, Peng J, Li Y, He L, Chen F, Zhang J and Ding J: Pharmacokinetic comparisons of rutaecarpine and evodiamine after oral administration of $\mathrm{Wu}-\mathrm{Chu}-\mathrm{Yu}$ extracts with different purities to rats. J Ethnopharmacol 139: 395-400, 2012.

82. Lin C, Pan X, Li W, Ma J, Pan J, Cai J, Wang X and Lin G: Simultaneous determination of evodiamine and rutecarpine in rabbit plasma by LC-ESI-MS and its application to pharmacokinetics. Pharmazie 66: 920-923, 2011.

83. Xia YY, Xu HY, Cai YY, Si DY and Liu CX: Simultaneous determination of evodiamine and evodine in beagle dog plasma using liquid chromatography tandem mass spectrometry. J Asian Nat Prod Res 15: 235-243, 2013.

84. Komatsu K, Wakame K and Kano Y: Pharmacological properties of galenical preparation. XVI. Pharmacokinetics of evodiamine and the metabolite in rats. Biol Pharm Bull 16: 935-938, 1993.

85. Jeng KF, Lin YH, Lin LC, Chou CJ, Tsai TH and Chen CF High-performance liquid chromatographic determination of evodiamine in rat plasma: Application to pharmacokinetic studies. J Chromatogr B Biomed Appl 668: 343-345, 1995.

86. Xu H, Li Q, Yin Y, Lv C, Sun W, He B, Liu R, Chen X and Bi K Simultaneous determination of three alkaloids, four ginsenosides and limonin in the plasma of normal and headache rats after oral administration of $\mathrm{Wu}-\mathrm{Zhu}-\mathrm{Yu}$ decoction by a novel ultra fast liquid chromatography-tandem mass spectrometry method: Application to a comparative pharmacokinetics and ethological study. J Mass Spectrom 48: 519-532, 2013.

87. Sun HZ, Fang ZZ, Cao YF, Sun XY and Hong M: Investigation of the in vitro metabolism of evodiamine: Characterization of metabolites and involved cytochrome p450 isoforms. Phytother Res 27: 705-712, 2013.

88. Zhang Z, Fang T, Zhou H, Yuan J and Liu Q: Characterization of the in vitro metabolic profile of evodiamine in human liver microsomes and hepatocytes by UHPLC-Q exactive mass spectrometer. Front Pharmacol 9: 130, 2018

89. Zhang YT, Zhang DF, Ge NY, Zhu GH, Hao C, Zhang Y and Chen RJ: Effect of evodiamine on CYP enzymes in rats by a cocktail method. Pharmacology 97: 218-223, 2016.

90. Xu H, Zhang T, Yang H, Xiao X, Bian Y, Si D and Liu C: Preparation of evodiamine solid dispersions and its pharmacokinetics. Indian J Pharm Sci 73: 276-281, 2011.

91. Tan Q, Liu S, Chen X, Wu M, Wang H, Yin H, He D, Xiong H and Zhang J: Design and evaluation of a novel evodiamine-phospholipid complex for improved oral bioavailability. AAPS PharmSciTech 13: 534-547, 2012

92. Grattagliano I, Diogo CV, Mastrodonato M, de Bari O, Persichella M, Wang DQ, Liquori A, Ferri D, Carratù MR, Oliveira PJ and Portincasa P: A silybin-phospholipids complex counteracts rat fatty liver degeneration and mitochondrial oxidative changes. World J Gastroenterol 19: 3007-3017, 2013.

93. Hu J, Chen D, Jiang R, Tan Q, Zhu B and Zhang J: Improved absorption and in vivo kinetic characteristics of nanoemulsions containing evodiamine-phospholipid nanocomplex. Int J Nanomedicine 9: 4411-4420, 2014

94. Zhao J, Liu S, Hu X, Zhang Y, Yan S, Zhao H, Zeng M, Li Y, Yang $\mathrm{L}$ and Zhang J: Improved delivery of natural alkaloids into lung cancer through woody oil-based emulsive nanosystems. Drug Deliv 25: 1426-1437, 2018.

95. Zhang X, Liu HM, Lei TT, Feng J and Zhang JQ: A preliminary study of pharmacokinetics of evodiamine hydroxypropyl- $\beta$-cyclodextrin inclusion complex. Nan Fang Yi Ke Da Xue Xue Bao 36: 548-551, 2016 (In Chinese).

96. Qiu C, Gao LN, Yan K, Cui YL and Zhang Y: A promising antitumor activity of evodiamine incorporated in hydroxypropyl- $\beta$-cyclodextrin: Pro-apoptotic activity in human hepatoma HepG2 cells. Chem Cent J 10: 46, 2016.

97. Xu L, Li W, Sadeghi-Soureh S, Amirsaadat S, Pourpirali R and Alijani S: Dual drug release mechanisms through mesoporous silica nanoparticle/electrospun nanofiber for enhanced anticancer efficiency of curcumin. J Biomed Mater Res A, Aug 10, 2021 (Online ahead of print). 
98. Rastegari E, Hsiao YJ, Lai WY, Lai YH, Yang TC, Chen SJ, Huang PI, Chiou SH, Mou CY and Chien Y: An update on mesoporous silica nanoparticle applications in nanomedicine. Pharmaceutics 13: 1067, 2021

99. Feng Y, Li NX, Yin HL, Chen TY, Yang Q and Wu M: Thermo- and $\mathrm{pH}$-responsive, lipid-coated, mesoporous silica nanoparticle-based dual drug delivery system to improve the antitumor effect of hydrophobic drugs. Mol Pharm 16: 422-436, 2019

100.Zou L, Chen F, Bao J, Wang S, Wang L, Chen M, He C and Wang Y: Preparation, characterization, and anticancer efficacy of evodiamine-loaded PLGA nanoparticles. Drug Deliv 23 908-916, 2016.

101. Li C, Cai G, Song D, Gao R, Teng P, Zhou L, Ji Q, Sui H, Cai J, Li Q and Wang Y: Development of EGFR-targeted evodiamine nanoparticles for the treatment of colorectal cancer. Biomater Sci 7: 3627-3639, 2019

102. Ge Y, Zhao Y and Li L: Preparation of sodium cholate-based micelles through non-covalent 1 bonding interaction and application as oral delivery systems for paclitaxel. Drug Deliv 23 $2555-2565,2016$

103. Zhang J, Li Y, Fang X, Zhou D, Wang Y and Chen M: TPGS-g-PLGA/Pluronic F68 mixed micelles for tanshinone IIA delivery in cancer therapy. Int J Pharm 476: 185-198, 2014.

104. Chen F, Zhang J, He Y, Fang X, Wang Y and Chen M: Glycyrrhetinic acid-decorated and reduction-sensitive micelles to enhance the bioavailability and anti-hepatocellular carcinoma efficacy of tanshinone IIA. Biomater Sci 4: 167-182, 2016.

105. Jiang J, Liu Y, Wu C, Qiu Y, Xu X, Lv H, Bai A and Liu X Development of drug-loaded chitosan hollow nanoparticles for delivery of paclitaxel to human lung cancer A549 cells. Drug Dev Ind Pharm 43: 1304-1313, 2017.

106. Wu S, Pan H, Tan S, Ding C, Huang G, Liu G, Guo J and Su Z: In vitro inhibition of lipid accumulation induced by oleic acid and in vivo pharmacokinetics of chitosan microspheres (CTMS) and chitosan-capsaicin microspheres (CCMS). Food Nutr Res 61: 1331658, 2017.

107. Wang S, Wang L, Shi Z, Zhong Z, Chen M and Wang Y: Evodiamine synergizes with doxorubicin in the treatment of chemoresistant human breast cancer without inhibiting P-glycoprotein. PLoS One 9: e97512, 2014.

108. Li YL, Pan YN, Wu WJ, Mao SY, Sun J, Zhao YM, Dong JY, Zhang DY, Pan JP, Zhang C and Lin NM: Evodiamine induces apoptosis and enhances apoptotic effects of erlotinib in wild-type EGFR NSCLC cells via S6K1-mediated Mcl-1 inhibition. Med Oncol 33: 16, 2016.

109. Pan X, Wang M, Wu Y, Lu X, Shang Y, Xu Y, Zhai Y, Li J, Li Z and Gong M: Identification of active ingredients in Wuzhuyu decoction improving migraine in mice by spectral efficiency association. Mol Med Rep 12: 1524-1534, 2015

110. Xu H, Niu H, He B, Cui C, Li Q and Bi K: Comprehensive qualitative ingredient profiling of chinese herbal formula $\mathrm{Wu}-\mathrm{Zhu}-\mathrm{Yu}$ decoction via a mass defect and fragment filtering approach using high resolution mass spectrometry. Molecules 21: 664 , 2016.

111. Wang D, Ge S, Chen Z and Song Y: Evodiamine exerts anticancer effects via induction of apoptosis and autophagy and suppresses the migration and invasion of human colon cancer cells. J BUON 24: 1824-1829, 2019.

112. Zhu LQ, Zhang L, Zhang J, Chang GL, Liu G, Yu DD, Yu XM, Zhao MS and Ye B: Evodiamine inhibits high-fat diet-induced colitis-associated cancer in mice through regulating the gut microbiota. J Integr Med 19: 56-65, 2021.

113. Ogasawara M, Matsubara T and Suzuki H: Inhibitory effects of evodiamine on in vitro invasion and experimental lung metastasis of murine colon cancer cells. Biol Pharm Bull 24: 917-920, 2001.

114. Shen H, Zhao S, Xu Z, Zhu L, Han Y and Ye J: Evodiamine inhibits proliferation and induces apoptosis in gastric cancer cells. Oncol Lett 10: 367-371, 2015.

115. Hu C, Gao X, Han Y, Guo Q, Zhang K, Liu M, Wang Y and Wang J: Evodiamine sensitizes BGC-823 gastric cancer cells to radiotherapy in vitro and in vivo. Mol Med Rep 14: 413-419, 2016

116. Huang H, Zhang Y, Liu X, Li Z, Xu W, He S, Huang Y and Zhang H: Acid sphingomyelinase contributes to evodiamine-induced apoptosis in human gastric cancer SGC-7901 cells. DNA Cell Biol 30: 407-412, 2011.

117. Sachita K, Kim Y, Yu HJ, Cho SD and Lee JS: In Vitro assessment of the anticancer potential of evodiamine in human oral cancer cell lines. Phytother Res 29: 1145-1151, 2015.
118. Wu Y, Wang J, Zhao J, Zhang Y, Sun Y, Chen J and Wang J: Gene regulation analysis of the effects of evodiamine on tongue squamous cell carcinoma. J Cell Biochem 120: 15933-15940, 2019.

119. Zhao S, Xu K, Jiang R, Li DY, Guo XX, Zhou P, Tang JF, Li LS Zeng D, Hu L, et al: Evodiamine inhibits proliferation and promotes apoptosis of hepatocellular carcinoma cells via the hippo-yes-associated protein signaling pathway. Life Sci 251 : $117424,2020$.

120. Hu CY, Wu HT, Su YC, Lin CH, Chang CJ and Wu CL: Evodiamine exerts an anti-hepatocellular carcinoma activity through a WWOX-dependent pathway. Molecules 22: 1175, 2017

121. Zhu H, Ge K, Lu J and Jia C: Growth inhibitor of human hepatic carcinoma HepG2 cells by evodiamine is associated with downregulation of PRAME. Naunyn Schmiedebergs Arch Pharmacol 392: 1551-1560, 2019.

122. Wang XN, Han X, Xu LN, Yin LH, Xu YW, Qi Y and Peng JY: Enhancement of apoptosis of human hepatocellular carcinoma SMMC-7721 cells through synergy of berberine and evodiamine. Phytomedicine 15: 1062-1068, 2008

123. Fang C, Zhang J, Qi D, Fan X, Luo J, Liu L and Tan Q: Evodiamine induces $\mathrm{G} 2 / \mathrm{M}$ arrest and apoptosis via mitochondrial and endoplasmic reticulum pathways in H446 and H1688 human small-cell lung cancer cells. PLoS One 9: e115204, 2014

124. Wang T, Qi D, Hu X, Li N, Zhang X, Liu H, Zhong C and Zhang J: A novel evodiamine amino derivative as a PI3K/AKT signaling pathway modulator that induces apoptosis in small cell lung cancer cells. Eur J Pharmacol 906: 174215, 2021.

125. Lin L, Ren L, Wen L, Wang Y and Qi J: Effect of evodiamine on the proliferation and apoptosis of A549 human lung cancer cells. Mol Med Rep 14: 2832-2838, 2016.

126. Jiang ZB, Huang JM, Xie YJ, Zhang YZ, Chang C, Lai HL, Wang W, Yao XJ, Fan XX, Wu QB, et al: Evodiamine suppresses non-small cell lung cancer by elevating $\mathrm{CD} 8^{+} \mathrm{T}$ cells and downregulating the MUC1-C/PD-L1 axis. J Exp Clin Cancer Res 39: 249,2020 .

127. Hong JY, Park SH, Min HY, Park HJ and Lee SK: Anti-proliferative effects of evodiamine in human lung cancer cells. J Cancer Prev 19: 7-13, 2014.

128. Tu YJ, Fan X, Yang X, Zhang C and Liang HP: Evodiamine activates autophagy as a cytoprotective response in murine Lewis lung carcinoma cells. Oncol Rep 29: 481-490, 2013.

129. Mohan V, Agarwal R and Singh RP: A novel alkaloid, evodiamine causes nuclear localization of cytochrome-c and induces apoptosis independent of p53 in human lung cancer cells. Biochem Biophys Res Commun 477: 1065-1071, 2016.

130. Huang YC, Guh JH and Teng CM: Induction of mitotic arrest and apoptosis by evodiamine in human leukemic T-lymphocytes. Life Sci 75: 35-49, 2004

131. Zhang Y, Zhang QH, Wu LJ, Tashiro SI, Onodera S and Ikejima T: Atypical apoptosis in L929 cells induced by evodiamine isolated from evodia rutaecarpa. J Asian Nat Prod Res 6: 19-27, 2004

132. Khan M, Bi Y, Qazi JI, Fan L and Gao H: Evodiamine sensitizes U87 glioblastoma cells to TRAIL via the death receptor pathway. Mol Med Rep 11: 257-262, 2015.

133. Wu WS, Chien CC, Liu KH, Chen YC and Chiu WT: Evodiamine prevents glioma growth, induces glioblastoma cell apoptosis and cell cycle arrest through JNK activation. Am J Chin Med 45 879-899, 2017

134. Liu AJ, Wang SH, Chen KC, Kuei HP, Shih YL, Hou SY, Chiu WT, Hsiao SH and Shih CM: Evodiamine, a plant alkaloid, induces calcium/JNK-mediated autophagy and calcium/mitochondria-mediated apoptosis in human glioblastoma cells Chem Biol Interact 205: 20-28, 2013.

135. Meng ZJ, Wu N, Liu Y, Shu KJ, Zou X, Zhang RX, Pi CJ, He BC, $\mathrm{Ke} Z \mathrm{Y}$, Chen L, et al: Evodiamine inhibits the proliferation of human osteosarcoma cells by blocking PI3K/Akt signaling. Oncol Rep 34: 1388-1396, 2015.

136. Zhou Y and Hu J: Evodiamine induces apoptosis, G2/M cell cycle arrest, and inhibition of cell migration and invasion in human osteosarcoma cells via Raf/MEK/ERK signalling pathway. Med Sci Monit 24: 5874-5880, 2018

137. Yang S, Chen J, Tan T, Wang N, Huang Y, Wang Y, Yuan X, Zhang $P$, Luo $J$ and Luo $X$ : Evodiamine exerts anticancer effects against 143B and MG63 cells through the Wnt/ $\beta$-catenin signaling pathway. Cancer Manag Res 12: 2875-2888, 2020.

138. Bai X, Meng H, Ma L and Guo A: Inhibitory effects of evodiamine on human osteosarcoma cell proliferation and apoptosis Oncol Lett 9: 801-805, 2015 
139. Hwang ST, Um JY, Chinnathambi A, Alharbi SA, Narula AS, Namjoshi OA, Blough BE and Ahn KS: Evodiamine mitigates cellular growth and promotes apoptosis by targeting the c-Met pathway in prostate cancer cells. Molecules 25: 1320, 2020.

140. Zhang T, Qu S, Shi Q, He D and Jin X: Evodiamine induces apoptosis and enhances TRAIL-induced apoptosis in human bladder cancer cells through mTOR/S6K1-mediated downregulation of Mcl-1. Int J Mol Sci 15: 3154-3171, 2014.

141. Shi CS, Li JM, Chin CC, Kuo YH, Lee YR and Huang YC: Evodiamine induces cell growth arrest, apoptosis and suppresses tumorigenesis in human urothelial cell carcinoma cells. Anticancer Res 37: 1149-1159, 2017.

142. Du J, Sun Y, Lu YY, Lau E, Zhao M, Zhou QM and Su SB: Berberine and evodiamine Act synergistically against human breast cancer MCF-7 cells by inducing cell cycle arrest and apoptosis. Anticancer Res 37: 6141-6151, 2017.

143. Wang KL, Hsia SM, Yeh JY, Cheng SC, Wang PS and Wang SW: Anti-proliferative effects of evodiamine on human breast cancer cells. PLoS One 8: e67297, 2013.

144. Du J, Wang XF, Zhou QM, Zhang TL, Lu YY, Zhang H and Su SB: Evodiamine induces apoptosis and inhibits metastasis in MDA-MB-231 human breast cancer cells in vitro and in vivo. Oncol Rep 30: 685-694, 2013.
145. Wei L, Jin X, Cao Z and Li W: Evodiamine induces extrinsic and intrinsic apoptosis of ovarian cancer cells via the mitogen-activated protein kinase/phosphatidylinositol-3-kinase/protein kinase B signaling pathways. J Tradit Chin Med 36: 353-359, 2016 (In Chinese).

146. Chen TC, Chien CC, Wu MS and Chen YC: Evodiamine from evodia rutaecarpa induces apoptosis via activation of JNK and PERK in human ovarian cancer cells. Phytomedicine 23: 68-78, 2016.

147. Liu N, Li Y, Chen G and Ge K: Evodiamine induces reactive oxygen species-dependent apoptosis and necroptosis in human melanoma A-375 cells. Oncol Lett 20: 121, 2020.

148. Lin H, Lin L, Choi Y and Michniak-Kohn B: Development and in-vitro evaluation of co-loaded berberine chloride and evodiamine ethosomes for treatment of melanoma. Int J Pharm 581 119278,2020

149. Yang J, Wu LJ, Tashiro S, Onodera S and Ikejima T: Nitric oxide activated by $\mathrm{p} 38$ and NF-kappaB facilitates apoptosis and cell cycle arrest under oxidative stress in evodiamine-treated human melanoma A375-S2 cells. Free Radic Res 42: 1-11, 2008.

150. Wang C, Wang MW, Tashiro S, Onodera S and Ikejima T: Evodiamine induced human melanoma A375-S2 cell death partially through interleukin 1 mediated pathway. Biol Pharm Bull 28: 984-989, 2005. 